Reviews in Digital Humanities • Vol. 2, No. 12

\title{
Review: Furnace and Fugue
}

\author{
Alicja Bielak ${ }^{1}$ \\ ${ }^{1}$ Centre for the History of Renaissance Knowledge
}

Published on: Dec 13, 2021

DOI: $10.21428 / 3 \mathrm{e} 88 \mathrm{f} 64 \mathrm{f} .6 \mathrm{f} 3 \mathrm{a} 23 \mathrm{ff}$

License: Creative Commons Attribution 4.0 International License (CC-BY 4.0). 


\title{
Project
}

Furnace and Fugue

Project Director

Allison Levy, Brown University

Project URL

https://furnaceandfugue.org/

Project Reviewer

Alicja Bielak, Polish Academy of Sciences

\section{Project Overview}

\begin{abstract}
Allison Levy
Furnace and Fugue: A Digital Edition of Michael Maier's Atalanta fugiens (1618) with Scholarly Commentary, edited by Tara Nummedal and Donna Bilak and published by University of Virginia Press (July 2020), brings to life in digital form an enigmatic 17thcentury text: Michael Maier's alchemical emblem book Atalanta fugiens. This intriguing and complex text from 1618 reinterprets Ovid's legend of Atalanta as an alchemical allegory in a series of fifty emblems, each containing text, image, and a musical score for three voices. Re-rendering Maier's multimedia masterpiece as an enhanced born-digital publication, Furnace and Fugue allows contemporary readers to hear, see, manipulate, and investigate Atalanta fugiens in ways that were perhaps imagined when it was composed but were simply impossible to realize before now.

Atalanta fugiens lends itself unusually well to today's digital tools. An interactive, layered digital edition provides accessibility and flexibility, presenting all the elements of the original book along with significant enhancements that allow for deep engagement by specialists and non-specialists alike: a fully searchable English translation sourced from a seventeenth-century manuscript housed in the Beinecke Rare Book and Manuscript Library at Yale University; high resolution, zoomable images; newly commissioned, manipulable vocal recordings of the book's music; a downloadable performance edition featuring modernized musical notation; and a multifunctional space that allows users to curate, save, and share their own selection and arrangement of Maier's emblems.
\end{abstract}


Furnace and Fugue makes possible the playful capabilities implied by Atalanta fugiens while also enabling and encouraging new interpretations of this early modern emblem book. Three short introductory essays invite readers to get acquainted with early modern alchemy, contemporary printing methods, and Maier himself. Eight extended interpretive essays explore Atalanta fugiens and its place in the history of music, science, and print and visual cultures in early modern Europe. These interdisciplinary essays include interactive features that clarify or advance the authors' arguments while positioning Furnace and Fugue as an original, uniquely engaging contribution to our understanding of early modern culture. Furnace and Fugue is particularly suitable for classroom adoption. This innovative resource has been published on an open access basis, making it available immediately, for free, to anyone.

Furnace and Fugue was developed under the auspices of Brown University's Digital Publications Initiative, generously supported by the Andrew W. Mellon Foundation. Additional support was provided by a Humanities Grant from the Gladys Krieble Delmas Foundation, as well as a Richard B. Salomon Faculty Research Award and a Seed/Bridge Grant from the Social Science Research Institute at Brown University. Full details on editorial practices, technical specifications, and team expertise can be found in "About the Project" on the publication website.

\section{Project Review}

\section{Alicja Bielak}

Furnace and Fugue is a digital edition of the emblem book Atalanta fugiens (1618) by German alchemist and physician Michael Maier. Each of 50 emblems in the work consists of etching (icon), motto, an epigram in German and Latin (subscription), and a "fugue" (music notation written for three voices). Four hundred years after its publication, the Furnace and Fugue edition fulfills Maier's dream that his emblems could be "seen, read, meditated [upon], understood, distinguished, sung and heard." The study of emblems - an early modern genre combining textual and visual elementshas resulted in a number of digital projects creating virtual emblem repositories and search engines (e.g. Emblematica Online and Emblem Project Utrecht). The aim of such projects is mainly search and comparison of themes, symbols, and motives enabled by Iconclass tagging system. Considering this background, Furnace and Fugue is outstanding for several reasons. 
The very choice of such a complex emblem collection necessarily requires an interdisciplinary team of experts from several fields, namely book historians, literary scholars, historians dealing with alchemy, musicologists, art historians, mathematicians, and experts in digital humanities. The involvement of specialists is reflected in the well-prepared transcriptions (text and musical notation) and a number of case studies. From a philological point of view, it is worth underscoring that this edition contains diplomatic as well as normalized transcription both in English and Latin. However, the authors have not provided critical apparatus in the form of extended commentaries on individual works; without such commentary, the works often prove puzzling. However, this function is partly fulfilled by inclusion of specialized studies that highlight new discoveries related to the work (e.g. L. Ludwig's study on the authorship of the musical compositions in the collection) and represent the first fully interdisciplinary attempt to study Maier's emblems.

The use of digital tools is suited to the content and form of this complex 17th-century work. Both encoding standards used to translate Maier's poems into English (TEI) and music notation (MEI) were deployed in the project, but they do not cover all the possibilities because, as the creators assert, they "capture more features than were able to be displayed in the digital edition and are available for re-use." Similarly as in the Iconclass system, each emblem includes "tag" description that allow readers to compare the themes and create their own collections. The interface of the edition, despite its complexity, is user-friendly due to the use of numerous plugins and JavaScript animation libraries, including GreenSock Animation API (GSAP), the GSAP ScrollToPlugin, ScrollMagic, Tumult Hype Pro, and the Waypoints JavaScript library. Particularly noteworthy is the way users can scroll through individual emblems with the transcription (located on the right side of the window) corresponding to the printed book (digitized leaves on the left side), which makes the study and presentation of individual works extremely easy. The inclusion of audio files (a recording of sung fugues) for all emblems and the way they are presented is also a very important facet of the project. The user is able to mute individual voices out of the three present in each fugue and follow their symmetrical construction through a lucid visualization of the piano roll (best represented by the Emblem 46 "De secretis Naturae"). It is important to emphasize that in this edition the interface itself serves as a research tool that enables a comparative analysis of all three elements: image, word, and music. As such, Furnace and Fugue is a model for similar projects analyzing multimedia works. 